\title{
Sacrococcygeal hydatid cyst: another entity in the differential diagnosis of sacrococcygeal chordoma. Case report
}

\author{
C Yegen MD, ${ }^{1}$ A F Ozer MD ${ }^{2}$ A O Aktan MD ${ }^{3}$ R Yalin $\mathrm{MD}^{4}$ \\ ${ }^{1}$ Assistant Professor of Surgery, ${ }^{2}$ Associate Professor of Neurosurgery, ${ }^{3}$ Associate \\ Professor of Surgery, ${ }^{4}$ Professor of Surgery, Marmara University School of Medicine, \\ Istanbul, Turkey.
}

\begin{abstract}
A case of hydatid disease of the sacrum with severe neurological symptoms, which was misdiagnosed preoperatively as a chordoma, is presented. The patient had significant improvement of the neurological symptoms after evacuation of the cyst. Sacral hydatid cysts must be considered in the differential diagnosis of sacrococcygeal chordoma.
\end{abstract}

Keywords: hydatid cyst; sacrum; chordoma.

\section{Introduction}

Hydatid cysts, caused by Echinococcus granulosus, are located in the bone in less than $1 \%$ of cases with this parasitic disease. ${ }^{1}$ Isolated sacrococcygeal location of the cyst is even rarer. Chordomas of the spinal column are also rare but the most common location is the sacrococcygeal area. Diagnosis of these rare pathologies may sometimes pose great difficulties. In this paper, a patient with severe neurological symptoms due to a sacrococcygeal hydatid cyst, who was preoperatively misdiagnosed as having a chordoma is presented.

\section{Case report}

A 46 year old male patient was admitted with complaints of low back pain and limping during walking. He also experienced increasing degrees of incontinence for stool and urine together with impotence for some 16 years.

On physical examination no palpable mass was found in the abdomen, over the sacrum or on digital rectal examination. Anal sphincter tone was totally lost and anal manometry revealed the resting pressure to be $0 \mathrm{cmH} 20$ and maximal sequeezing pressure $15 \mathrm{cmH} 2 \mathrm{O}$. On neurological examination, there was weakness of plantar flexion of the right foot with loss of the achilles reflex. Sensory loss was noted in

Correspondence: A Ozdemir Aktan MD, Marmara University Hospital, Department of General Surgery, Altunizade 81190 Istanbul, Turkey. the saddle area. Urinary flow studies were not carried out but the patient was completely incontinent for urine requiring catheterisation.

Plain xrays of the pelvis revealed near complete destruction of the sacrum, and on magnetic resonance imaging (MRI) a multicystic soft tissue mass extending down from the L5 vertebra up to the coccyx was seen (Fig 1). No other masses were evident in the abdominal cavity or chest.

With a preoperative diagnosis of sacral chordoma a combined anterior-posterior approach

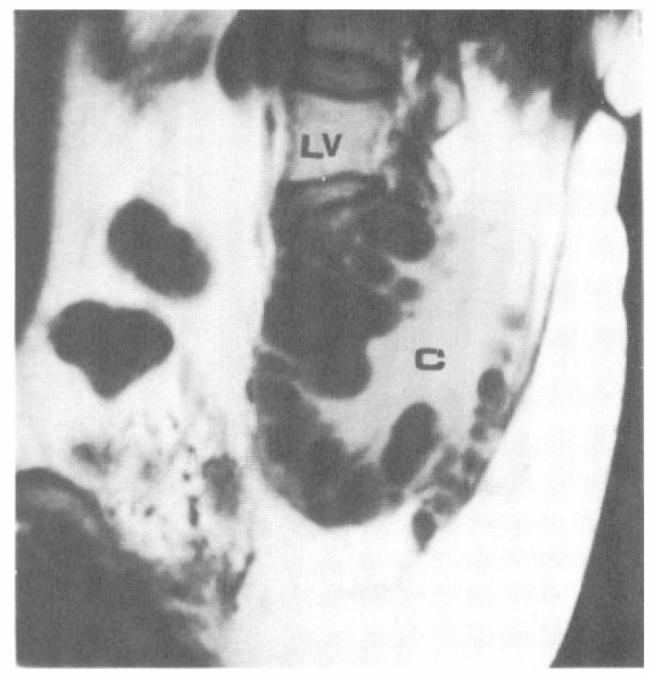

Figure 1 The magnetic resonance imaging of the sacral hydatid cyst. $(\mathrm{C}=$ cyst, $\mathrm{LV}=$ lumbar vertebra). 
was planned. At the operation, after a midline laparotomy, the rectum was completely mobilised to reveal a multivesicular hydatid cyst of the sacrum. The diagnosis was ascertained by aspirating the characteristic 'spring water' of the cyst which was later inactivated with $0.5 \%$ AgNO3 and precautions were taken to prevent spillage. Then the cyst was opened and the daughter cysts evacuated together with bone fragments. The large cystic cavity was again irrigated with povidone iodine and a large sump drain was left in situ. Postoperatively the developing cystic cavity infection was treated by irrigations through the sump drain, and the patient was discharged on the 29th day. No further medical treatment was given. Three months after the operation the patient's pain was totally relieved and the control MRI revealed no further cysts. There was a significant clinical improvement in urinary and stool continence although this was not reflected by anal manometry. There was no improvement in sexual functions.

\section{Discussion}

Preoperative diagnosis of hydatid disease is essential because inadvertent opening of the cyst and spillage of the cystic fluid and contents may result in severe complications; namely anaphylaxis and recurrence. ${ }^{2}$ To prevent these, the cystic contents must be devitalised using $0.5 \%$ AgNO3, povidone iodine or hypertonic saline $e^{1,3}$ and the neighbouring organs and peritoneum must be protected with packs soaked with one of these agents. If the diagnosis is not made preoperatively, intraoperative recognition will depend on the experience of the surgeon. Although any cyst in any part of the body may be considered to be a hydatid cyst in areas where this disease is endemic, this is hardly true for western countries.

The most common location of hydatid disease is the liver followed by the lung and spleen. ${ }^{1}$ About $1 \%$ occurs in bone, and a very unusual localisation is in the sacrococcygeal area..$^{2,4-10}$

Chordomas are usually located in the sacrococcygeal area ${ }^{11}$ and have a lobulated and gelatinous structure which may be confused with cysts on computerised tomography or MRI.

Bone hydatid cysts give clinical symptoms ranging from pain to pathological fractures and paraplegia. ${ }^{8.9}$ The severe neurological symptoms encountered may fail to reverse after treatment. The high rate of neurological symptoms and complications seen in bone cysts may be due to the high intracystic pressure of viable hydatid cysts. ${ }^{12}$ The neurological symptoms are expected to regress after surgery if related to the cyst but regression is unlikely if bony destruction is present. But the patient presented in this paper had significant reversal of the neurological symptoms despite their long duration.

Although there is good experimental evidence for the use of perioperative mebendazole, albendazole or praziquantel in reducing recurrences, ${ }^{13.14}$ medical treatment of bone hydatid cysts has been used as an adjunct to surgery with unpredictable results. ${ }^{8.15 .16}$ The surgical treatment of choice is total excision but this is rarely possible. ${ }^{7.8}$ Our patient was treated with inactivation and evacuation of the cyst followed by external tube drainage, because of the technical impossibility of excising the cyst. External tube drainage is also our preferred method of treatment for other complicated abdominal hydatid cysts or when there is no omentum available to pack into the cystic cavity which was the case in this patient. ${ }^{17}$ The postoperative infection of the cystic cavity was treated conservatively and was thought to be helpful in devitalising any viable parasites that may have been left in the large cystic cavity. Infected cysts are always nonviable according to our previous experiences. ${ }^{12}$ The precautions taken and the inactivation of the cystic cavity with both AgNO3 and povidone iodine should minimise the risk of recurrence. The patient was given no further treatment.

Preoperative diagnosis of hydatid disease is essential to minimise the complications of this disease. Even in a rare localisation such as the sacrococcygeal area, hydatid disease must be borne in mind especially in endemic areas or in patients coming from endemic areas. The presented patient was misdiagnosed preoperatively as having a chordoma, probably because chordoma is the most common tumour of that region. 


\section{References}

1 Morris DL (1992) Diagnosis of hydatid disease. In: D L Morris, K S Richards, editors. Hydatid Disease. 1st ed. Butterworth-Heinemann, Oxford: 25-56.

2 Heinze J, Junginger W, Muller G, Gaebel G (1987) Anaphylactic shock during excision of an intraosseous Echinococcus granulosus cyst. Anaesthesist 36: 659-661.

3 Gokce O, Gokce C, Yilmaz M, Huseyinoglu K, Gunel S (1991) Povidone-iodine in experimental peritoneal hydatidosis. Brit J Surg 78: 495-496.

4 Pamir MN, Akalan N, Ozgen T, Erbengi A (1984) Spinal hydatid cysts. Surg Neurol 21: 53-57.

5 Akyildiz AN, Ozbilen MS, Goksu N (1991) Hydatid cyst of the pterygopalatine fossa. J Oral Maxillofac Surg 49(1): 87-8.

6 Bouras A, Larde D, Mathieu D, Delepine G, Benameur C, Ferrane J (1984) The value of computed tomography in osseous hydatid disease (Echinococcosis). Sketetal Radiol 12(3): 192-195.

7 Ruelle A, Boccardo M, Lasio G, Severi P (1985) Primary vertebral hydatidosis. Rev Neurol 55(5): $332-337$.

8 Kaoutzanis M, Anagnostopoulos D, Apostolou A (1989) Hydatid disease affecting the vertebrae. Acta Neuro Chir 98: 60-65.

9 Rollinson PD, Geytenbeek RJ (1987) Hydatid disease of bone. Afr Med J 71: 727-728.

10 Ozer AF, Ozek MM, Pamir MN, Erzen C (in press) Magnetic resonance imaging of spinal hydatid disease. Paraplegia.

11 Buyukgebiz O, Aktan AO, Dosluoglu H, Esemenli T, Soylemezoglu F (1991) Sacrococcygeal chordoma. A case report and review of the literature. Marmara Med J 2(4): 75-77.

12 Yalin R, Aktan AO, Yegen C, Dosluoglu H (1992) Significance of intracystic pressure in abdominal hydatid cysts. Br J Surg 79: 1182-1183.

13 Sayek I, Cakmakci M (1986) The effect of prophylactic mebendazole in experimental peritoneal hydatidosis. Surg Gynecol Obstet 163: 351-353.

14 Taylor DH, Morris DL (1989) Combination chemotherapy is more effective in postspillage prophylaxis for hydatid disease than either albendazole or praziquantel alone. Br J Surg 76: 954.

15 Fournier JP, Marty P, Bernard E, Leloire P, Dellamonica P, Le Fichoux Y (1985) Spinal hydatidosis treated by albendazole. Pathol Biol 33: 611-613.

16 Dellamonica P, Le Fichoux Y (1986) Spinal hydatidosis; Failure of albendazole. Pathol Biol 34: $295-296$.

17 Aktan AO, Yalin R, Yegen C, Okboy N (in press) Surgical treatment of hydatid cysts of the liver. Acta Chir Belg. 